\title{
EFFECT OF MOLECULAR WEIGHT ON THE YIELD BEHAVIOUR OF EPY EPOXY COMPOUND
}

\author{
Magdalena Urbaniak ${ }^{1}$
}

1 Department of Mechanics and Machine Elements, Faculty of Mechanical Engineering and Mechatronics, West Pomeranian University of Technology, Piastow 19, 70-310 Szczecin, Poland, e-mail: magdalena.urbaniak@ zut.edu.pl

Received: 2016.08 .25

Accepted: 2016.10.18

Published: 2016.12.01

\begin{abstract}
A series of epoxy networks with molecular weight between crosslinks $\left(M_{c}\right)$ ranging from 117 to $508 \mathrm{~g} / \mathrm{mol}$ were investigated by employing as DSC and DMA methods and compression testing over a broad range of test temperatures (from 20 to $120^{\circ} \mathrm{C}$ ) and strain rates (from 0.0208 to $20.8 \mathrm{~min}^{-1}$ ). Mechanical characteristics vs. testing temperature and strain rate developed in relation to working conditions of EPY compound applied for machine foundation chocks as well as effect of crosslinking on glass transition temperature $\left(\mathrm{T}_{\mathrm{g}}\right)$ presented in this paper let to find out the effect of molecular architecture composed chiefly by $\mathrm{M}_{\mathrm{c}}$ on the thermal and mechanical properties that govern yield behaviour of the material. The investigations carried out in a.m. ranges of testing temperatures and strain rates showed that whichever change of $M_{c}$ is related to the change in crosslink density causing relative shift in the $T_{g}$ of the compound. However, a sensitivity of the polymer material on changes in strain rate falls down with growth of testing temperature. Obtained results prove that yielding in EPY compound can be examined in categories of the Eyring's plastic flow model in which yielding is described.
\end{abstract}

Keywords: epoxy network, molecular weight between crosslinks, glass transition temperature, yield behaviour.

\section{INTRODUCTION}

Over the past 50 years the relationships between molecular structure and both thermal and mechanical behaviour in amorphous glassy polymers has been subjected to extensive studies $[2,11]$ which are important from the engineering point of view. Their results, by employing a variety of experimental techniques, provide information on structure - property correlation which is essential for optimizing polymer composition and cure process conditions to meet specific end-use requirements $[14,22]$. Nevertheless, determining the role that a network architecture plays on the thermal and mechanical behaviour of thermoset systems, especially epoxy ones, is complicated by the wide variety of crosslinking agents and epoxy resins available. For that reason in the majority of such studies on epoxy systems, the molecular weight between crosslinks $\left(M_{\mathrm{c}}\right)$ is the only network variable controlled $[3,16,24,28]$. This parameter is related to the crosslink density and can be varied by changing the stoichiometric ratio and the degree of cure $[21,24]$ since while curing the chemical reaction between resin and the curing agent develops three dimensional crosslinked polymeric chains. It is well recognized that the physical and thermo-mechanical properties of epoxy systems are controlled by the degree of cure (also called crosslink density) and the flexibility of chains between crosslinks alike. 
Epoxy networks are exemplar ones for investigating the relationship between molecular architecture and material properties due to the accuracy with which the molecular weight between crosslinks $\left(M_{\mathrm{c}}\right)$ can be controlled [13]. However, it is significantly difficult to create a complete description how the yield behaviour of glassy polymers is affected by stress state, strain rate, temperature and $M_{c}$ due to a variety of network structures $[5,13]$.

The presented results of strength tests and experimental investigations obtained for the EPY compound by thermal (DSC) and dynamic mechanical (DMA) methods can contribute to understanding the correlation between molecular structure of epoxy materials and their thermomechanical behaviour manifested by e.g. stress/ strain rate, yield stress and moduli.

The EPY compound is the result of many years of scientific research on machine foundation carried out at the Mechanics and Machine Elements Department of the West Pomeranian University of Technology (formerly the Szczecin University of Technology) in close cooperation with the Polish shipbuilding industry [10]. The EPY compound has now found wide range of applications as chocking material not only in foundations of ship's and offshore machineries and installations but also in seating of many various heavy land-based machines used in mining, power industry and other fields of heavy industry and building engineering [10, 27]. Using the EPY material together with the cast-in-place technology of foundation chocks manufacturing provides significant technical and economic benefits which are extended throughout the service life of machines. It is also worth mentioning that actually only three chocking materials in the world, including the EPY compound, have got approval and quality certificates of industrial research institutes as well as the approvals of European ship engine producers and worldwide classification societies supervising ship building and repairs [10].

The aim of investigations on the yield behaviour presented in this work was:

- to establish relationships between the macroscopic mechanical behaviour of the EPY compound and its molecular weight between crosslinks $\left(M_{\mathrm{c}}\right)$ by means of flexion and compression testing in a wide range of changes of temperature, strain rate and deformation frequency,
- to show that the behaviour of the investigated compound is determined mainly by glass transition temperature which depends on the molecular architecture of the formed network.

\section{EXPERIMENTAL METHODS AND MEASUREMENT}

\section{Materials}

The main components of the investigated compound with trade name EPY (from Marine Service Jaroszewicz) are: two domestic epoxy resins and an aliphatic curing agent. The compound is completed with additives bestowing the appropriate technological and utility properties upon the material used in practice for foundation chocks [10].

\section{Sample preparation}

The samples used for postcuring investigations (using DSC method) and thermomechanical properties ones (by means of DMA) were cast in steel forms in the shape of $50 \times 10 \times 5$ $\mathrm{mm}$ rectangular bars and for compression tests as $\phi 20 \times 25 \mathrm{~mm}$ cylinders cured at $22 \pm 1^{\circ} \mathrm{C}$ for $24 \mathrm{~h}$. Such prepared samples were additionally postcured at various temperatures of $40,60,80$, 100 or $120^{\circ} \mathrm{C}$ for $2 \mathrm{~h}$.

\section{Method of testing}

\section{DSC measurements}

The course of the postcuring reaction of the epoxy material was investigated using the differential scanning calorimeter DSC Q100 (TA Instruments).

The samples (approx. $20 \mathrm{mg}$ ) were subjected to two heating cycles in DSC, at the rate of $10^{\circ} \mathrm{C} /$ min from $-50^{\circ} \mathrm{C}$ (under nitrogen atmosphere). Because an endothermic peak had appeared in the first heating cycle, the heating of the sample was stopped just beyond this peak, where postcuring was just initiated. Then the sample was requenched to the initial temperature $\left(-50^{\circ} \mathrm{C}\right)$ and subjected to the second cycle of heating carried out at the same rate up to $250^{\circ} \mathrm{C}$, in order to determine an accurate value of the glass transition temperature $\left(T_{g}\right) . T_{g}$ was determined in thermograms DSC as the point of half height of $\Delta C_{p}$, when the polymer passes from the glassy state to the rubbery state. 


\section{DMA measurements}

The dynamic mechanical properties in flexion of the tested compound were determined with the DMA MK-II dynamic thermal analyzer of Polymer Laboratories. The testing was carried out on three-point bending mode with an oscillating frequency of $1 \mathrm{~Hz}$ at temperatures ranging from -100 to $250^{\circ} \mathrm{C}$ and at the heating rate of $3^{\circ} \mathrm{C} / \mathrm{min}$ under nitrogen atmosphere. Evolution of storage modulus $\left(E^{\prime}\right)$ and loss modulus $\left(E^{\prime \prime}\right)$ were registered during the temperature-scanning experiments. The $T_{g}$ is determined by maximum peak of the $E^{\prime \prime}$.

\section{Molecular weight and crosslink density}

With an assumption that the material will behave as an ideal elastomer in rubbery regime, average molecular weight of the material between cross-links $\left(M_{c}\right)$ is calculated by means of the rubber elasticity theory, using $[9,12,29]$ :

$$
G^{\prime}=\frac{E^{\prime}}{3}=\frac{\phi \rho R T}{M_{c}}
$$

where: $G$ ' and $E$ ' are rubbery shear modulus and rubbery elastic modulus, respectively. The $\rho$ represents the material's density at temperature $T, R$ is the universal gas constant, and the front factor $\phi$ is a correction factor for free, unreacted chain ends which is defined as the ratio between mean square end-to-end distance of a networked chain and the length of a randomly coiled chain [23].

It is assumed that while determining molecular weight using Eq. (1) the value of $E$ ' corresponds to the temperature $T_{g}+40^{\circ} \mathrm{C}$ in the rubbery state $[12$, 23]. The $\rho$ is calculated by weighing test samples (acc. to ISO 1183) at room temperature $\left(T=23^{\circ} \mathrm{C}\right)$ and the $\phi$ is assumed as $0.75[20,21,23]$.

\section{Compression tests}

Compression tests of the EPY compound at various temperatures and strain rates were performed by means of the INSTRON 8501 Plus testing machine equipped with a heating chamber. The testing temperatures were raised by every 10 ${ }^{\circ} \mathrm{C}$ in the range from room temperature to the temperature of $20^{\circ} \mathrm{C}$ above $T_{g}\left(T_{g}+20^{\circ} \mathrm{C}\right)$ determined by DSC. The samples of the EPY compound were kept in the heating chamber of the testing machine before compression tests at determined temperature in order to become heated in full volume. The time of its heating (from 5 to $30 \mathrm{~min}$ ) was controlled by means of adequate ancillary sample using a thermocouple. Series of samples (consisting of 5 pieces) prepared in this way were subjected to uniaxial compression (in the chamber) up to the failure at various strain rates differing by order of magnitude from 0.0208 to 20.8 $\mathrm{min}^{-1}$ (corresponding to the crosshead speed from 0.13 to $130 \mathrm{~mm} / \mathrm{min}$, respectively). To minimize the friction between the compression platens and the polymer specimen, the contacting surfaces were lubricated. The characteristics of compression and the values of selected strength parameters of the samples were determined in reference to the initial cross-section area (according to the assumed assignations of the ISO 604 standard).

The yield stress value $\left(\sigma_{y}\right)$ was defined [6] as the point where the stress passed trough the maximum in the stress - strain curve or at the middle of an obvious "knee" in this curve (when a.m. maximum was not observed).

The true yield stress $\left(\sigma_{y T}\right)$ assuming constant volume deformation was calculated using equation [30]:

$$
\sigma_{y T}=\frac{P_{y}}{A_{0}}\left(1-\varepsilon_{y}\right)
$$

where: $P_{y}$ is the load at yield point, $A_{0}$ is the initial cross-sectional area, and $\varepsilon_{y}$ is the yield strain.

Both the compressive strength $\left(\sigma_{M}\right)$ and the Young's modulus $(E)$ corresponding to their standard definitions were determined using the stress - strain curve.

\section{RESULTS AND DISCUSSION}

\section{Glass transition temperature}

The glass transition temperatures of the postcured EPY epoxy compound at various temperatures collected in Table 1 show that increase of postcure temperature induce both higher crosslink density and a growth in $T_{g}$. As expected, since DMA is a dynamic technique and $T_{g}$ is frequency dependent, DMA values of $T_{g}^{\text {'s }}$ are higher (by $2-4^{\circ} \mathrm{C}$ ) than the corresponding DSC values 
Table 1. Some viscoelastic properties od EPY compound

\begin{tabular}{|c|c|c|c|c|c|}
\hline \multirow{2}{*}{$\begin{array}{l}\text { Postcure temperature } \\
\qquad T_{c}\left[{ }^{\circ} \mathrm{C}\right]\end{array}$} & \multirow[t]{2}{*}{ Density $\rho\left[\mathrm{g} / \mathrm{cm}^{3}\right]$} & \multicolumn{2}{|c|}{$\begin{array}{c}\text { Glass transition temperature } \\
\mathrm{T}_{\mathrm{g}}\left[{ }^{\circ} \mathrm{C}\right]\end{array}$} & \multirow{2}{*}{$\begin{array}{c}\text { Storage } \\
\text { modulus E' at } \\
\mathrm{T}_{\mathrm{g}}+40[\mathrm{MPa}]\end{array}$} & \multirow{2}{*}{$\begin{array}{l}\text { Molecular weight } \\
\mathrm{M}_{\mathrm{c}}[\mathrm{g} / \mathrm{mol}]\end{array}$} \\
\hline & & DSC & DMA & & \\
\hline 22 & 1.564 & 38.6 & 43.2 & 17.1 & 507.9 \\
\hline 40 & 1.566 & 54.3 & 58.3 & 36.4 & 238.1 \\
\hline 60 & 1.572 & 80.3 & 82.5 & 53.4 & 163.2 \\
\hline 80 & 1.575 & 95.6 & 98.2 & 61.1 & 142.7 \\
\hline 100 & 1.571 & 107.9 & 109.6 & 71.8 & 121.3 \\
\hline 120 & 1.570 & 110.6 & 112.4 & 73.8 & 117.2 \\
\hline
\end{tabular}

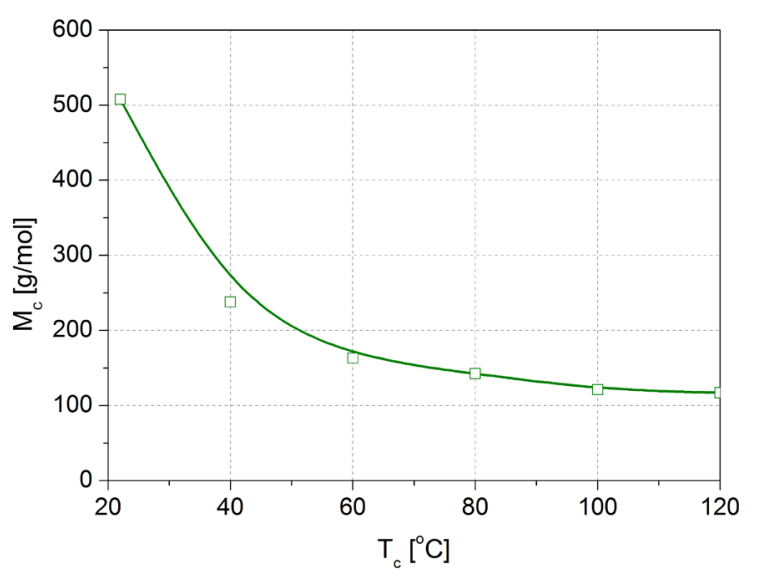

Fig. 1. Effect of postcure temperature $\left(T_{c}\right)$ on molecular weight $\left(M_{c}\right)$ of the EPY compound

of $T_{g}$ 's due to the measurement of extrinsic mechanical properties rather than intrinsic heat capacity and the poorer temperature control of the instrument.

\section{Molecular weight}

The molecular weight of the EPY compound, calculated by substituting rubbery state storage modulus (see Table 1) into Eq.(1), is plotted with its postcure temperatures in Fig. 1. The lowest molecular weight compound indicates that most of the resin chain ends are crosslinked by aliphatic reactants. It can be observed that in the proximity of postcure temperature $\left(T_{c}\right)$ equal to glass transition temperate of the fully reacted the EPY material $T_{g \infty}=111,2^{\circ} \mathrm{C}[26]$ the value of $M_{c}$ becomes stabilized.

\section{Correlation between $T_{g}$ and $M_{c}$}

The $T_{g}$ is plotted with the inverse of $M_{c}$ in Figure 2 to illustrate the effect of molecular weight on glass transition temperature of the postcured EPY compound. A linear correlation between $T_{g}$ and 1/ $M_{c}$ is clearly evident here. With increasing crosslink density, molecular mobility decreases due to additional tie points in network and it results in $T_{g}$ growth. These observations are in agreement with the trends reported earlier in the literature $[7,12,21,23]$.

The correlation between $T_{g}$ and $M_{c}$ can be described in the form of Nielsen's empirical equation [18]:

$$
T_{g}=T_{g 0}+\frac{\zeta}{M_{c}}
$$

where: $T_{g 0}$ is the glass transition temperature of the uncrosslinked polymer, $\xi$ is a parameter proportional to the molecular weight of the unreacted resin and to the ratio of incremental free volume contributions for the resin and the curing agent [28]. The slope of $T_{g}$ vs. $1 / M_{c}$ curve represents $\zeta$. In the current investigation $\zeta$ is measured to be $1.1 \times 10^{4} \mathrm{~g} / \mathrm{mol}{ }^{\circ} \mathrm{C}$.

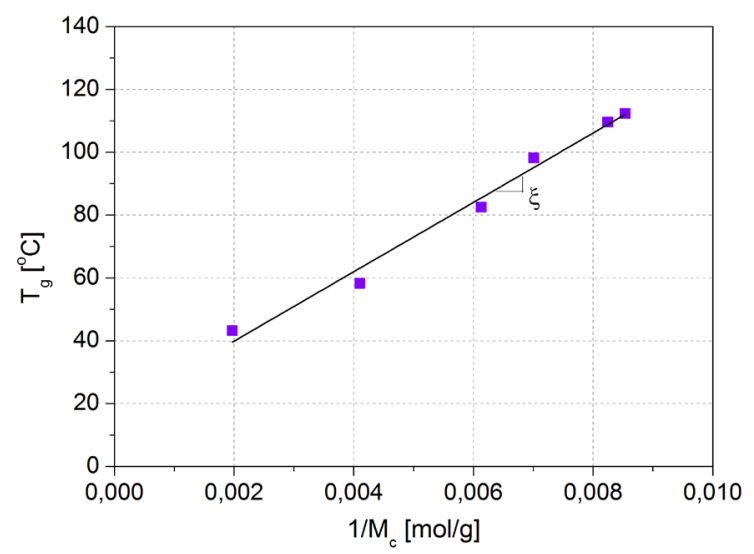

Fig. 2. Effect of molecular weight $\left(M_{c}\right)$ on the $T_{g}$ for the EPY compound 


\section{Effect of temperature on mechanical characteristics}

Mechanical behaviour of the EPY compound samples cured (at $22 \pm 1^{\circ} \mathrm{C}$ for $24 \mathrm{~h}$ ) and postcured additionally (at $80^{\circ} \mathrm{C}$ for $2 \mathrm{~h}$ ) which were subjected to compressive tests at a strain rate of 0.208 $\mathrm{min}^{-1}$ in the test temperature range from $21^{\circ} \mathrm{C}$ up to $T_{g}+20^{\circ} \mathrm{C}$ is shown as adequate characteristics in the stress - strain co-ordinate system plotted in Figs. $3 \mathrm{a}$ and $3 \mathrm{~b}$, respectively.

The stress - strain curves obtained at successive test temperatures within a.m. range preserve their typical shape up to the glass transition temperature $\left(T_{g}\right)$.

In the curves obtained at 21 and $30^{\circ} \mathrm{C}$ (Fig. 3a) for the EPY compound samples cured at $22 \pm 1{ }^{\circ} \mathrm{C}$ only (of which the $T_{g}$ value determined by DSC method equals $38.6^{\circ} \mathrm{C}$ ) a proportional increase is observed first (linear elastic stadium) and then
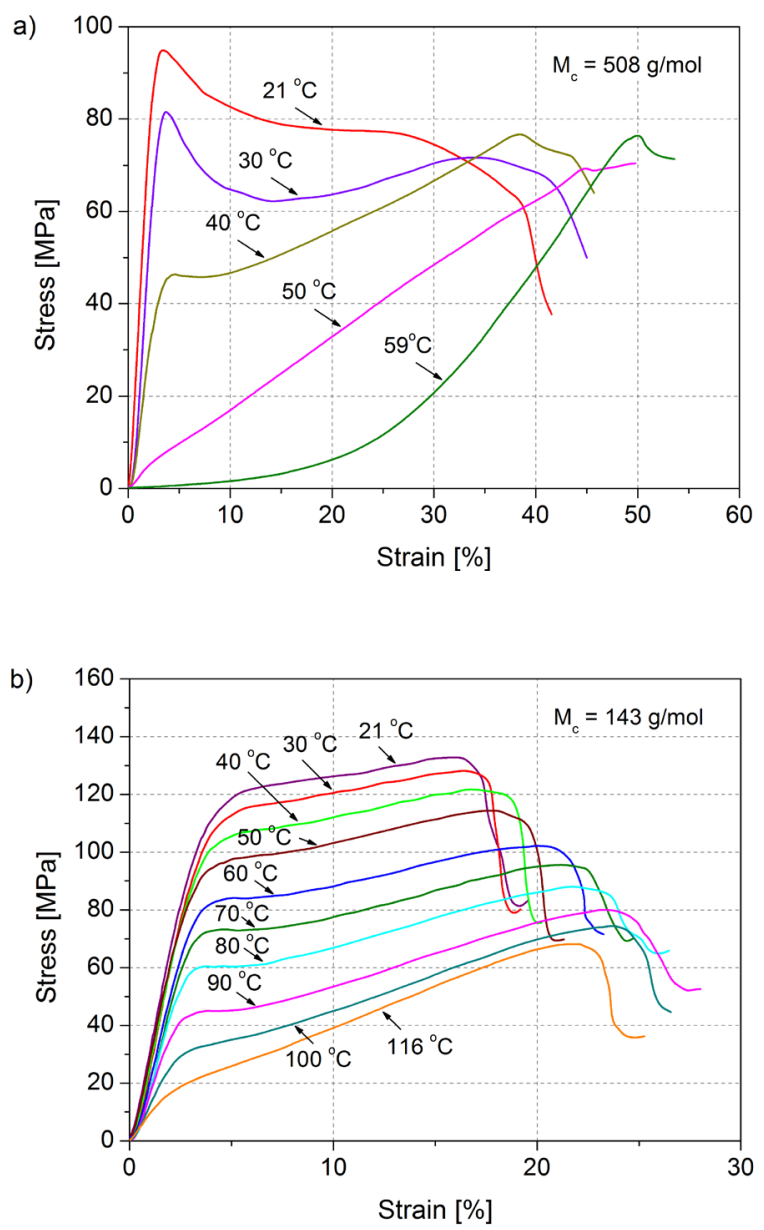

Fig. 3. Compressive stress - strain curves for the EPY compound with $M_{c}=508 \mathrm{~g} / \mathrm{mol}$ (a) and $M_{c}=143$ $\mathrm{g} / \mathrm{mol}(\mathrm{b})$, obtained at a standard strain rate $(0.208$ $\mathrm{min}^{-1}$ ) at various temperatures the curves are "bent" (non-linear elastic stadium) reaching a peak that appoints the maximum stress $\sigma_{M}$ called the compressive strength. The $\sigma_{M}$ value for the material cured in this way is identical with compressive stress called the yield stress $\left(\sigma_{y}\right)$. Afterwards, a strain softening stadium follows, and then a wide plateau of the curve (nearly perfect "plastic" flow stadium) is observed. Finally, the curves fall down suddenly and the samples burst without splinters.

Concerning the stress - strain curves obtained in the test temperature range from 20 to $100^{\circ} \mathrm{C}$ (Fig. 3b) for the EPY compound samples postcured at $80^{\circ} \mathrm{C}$ (of which the $T_{g}$ value equals $95.6^{\circ} \mathrm{C}$ ) one can observe after a fast increase in the beginning (linear elastic stadium) that the curves are "bent" forming specific knees. The yield stress $\left(\sigma_{y}\right)$ of the material is being assumed at a point in the middle of the knee. Afterwards, the curves are passing through a region of somewhat rising plateau (plastic flow stadium with slight strengthening) ending with a gentle peak that determines maximal compressive stress called the compressive strength $\left(\sigma_{M}\right)$. Behind this peak the curves fall down suddenly (failure stadium) and the samples burst without splinters.

The courses of the compression curves obtained at test temperatures higher than $T_{g}$ of the EPY compound have somewhat different character. The curves obtained at test temperatures of 50 and $59^{\circ} \mathrm{C}$ (Fig. 3a) for the material cured only as well as the curve obtained at $116^{\circ} \mathrm{C}$ (Fig. 3b) for the postcured material have their courses where only vast strain stadium can be noticed with almost linear strain increase up to the peak that determines the compressive strength $\left(\sigma_{M}\right)$ of the material. Behind this peak the curves fall down into failure stadium directly (a lack of "plastic" flow stadium).

The obtained results show (Fig. 3) that the yield stress $\left(\sigma_{y}\right)$ and the compressive strength $\left(\sigma_{M}\right)$ of the investigated material decrease distinctly in raised temperature conditions of testing.

\section{Effect of strain rate on mechanical characteristics}

Mechanical behaviour of the EPY compound samples cured (at $22 \pm 1^{\circ} \mathrm{C}$ for $24 \mathrm{~h}$ ) and additionally postcured (at $80{ }^{\circ} \mathrm{C}$ for $2 \mathrm{~h}$ ) which were subjected to compressive tests at temperature of $21^{\circ} \mathrm{C}$ (Fig. 4a) as well as $80^{\circ} \mathrm{C}$ (Fig. 4b) performed at four various strain rates $\dot{\varepsilon}=0.0208$; 

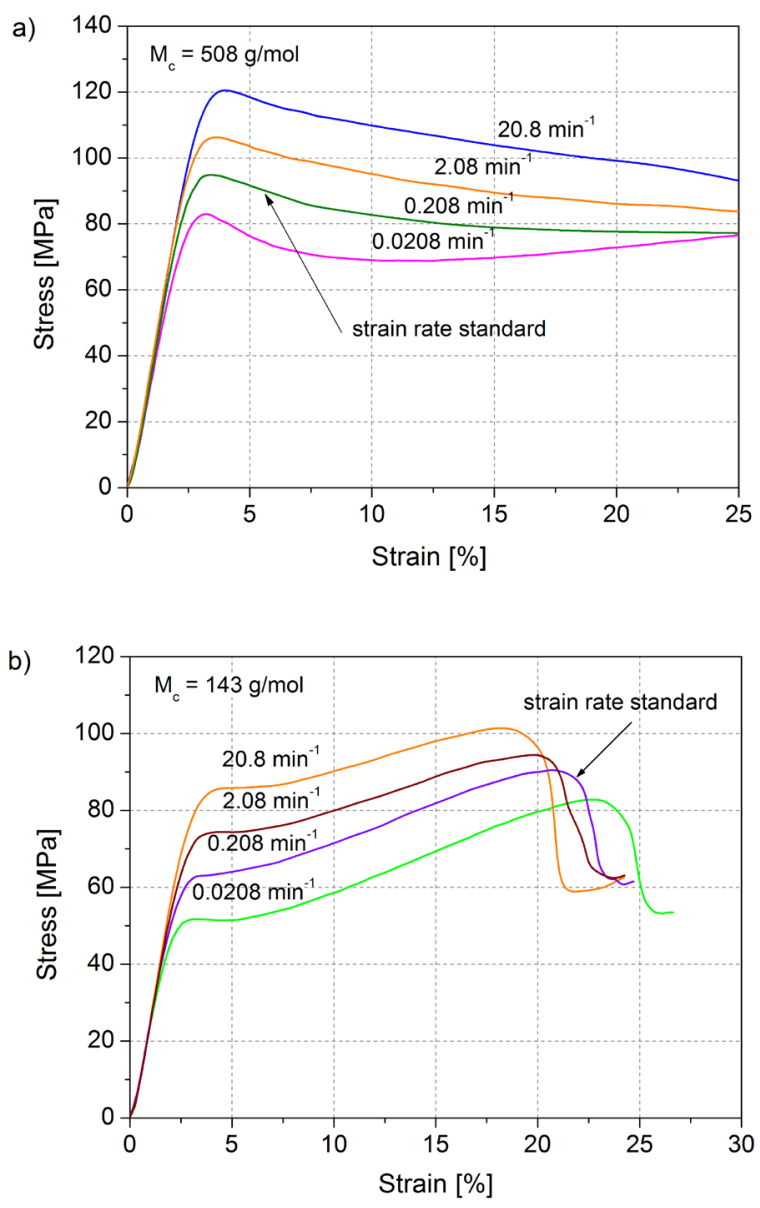

Fig. 4. Compressive stress - strain curves for the EPY compound with $M_{c}=508 \mathrm{~g} / \mathrm{mol}$ (a) and $M_{c}=143 \mathrm{~g} /$ mol (b), obtained at various strain rates at test temperature of: $21^{\circ} \mathrm{C}$ and $80^{\circ} \mathrm{C}$, respectively

$0.208 ; 2.08$ and $20.8 \mathrm{~min}^{-1}$ is shown as adequate characteristics in the stress - strain co-ordinate system plotted in Figs. 4a and 4b, respectively. The curve courses can be indicative of high sensitiveness for the EPY compound to a change of strain rate regardless of its $M_{c}$ value. Increasing of strain rate manifests itself with an increase of yield stress $\left(\Sigma_{y}\right)$ and compressive strength $\left(\sigma_{M}\right)$ of the material as well.

\section{Young modulus and storage modulus dependencies}

The compressive tests show how temperature, $M_{c}$ and strain rate affect modulus $E$ and true yield stress $\left(\sigma_{v T}\right)$ of the investigated material. The relationship between $E$ and testing temperature (ranging from 21 to $T_{g}+20^{\circ} \mathrm{C}$ ) for the EPY compound samples with various $M_{c}$ values (from 117 to $508 \mathrm{~g} / \mathrm{mol}$ ) determined at the strain rate of 0.208 $\mathrm{min}^{-1}$ is shown in Figure 5. It shows that the $E$

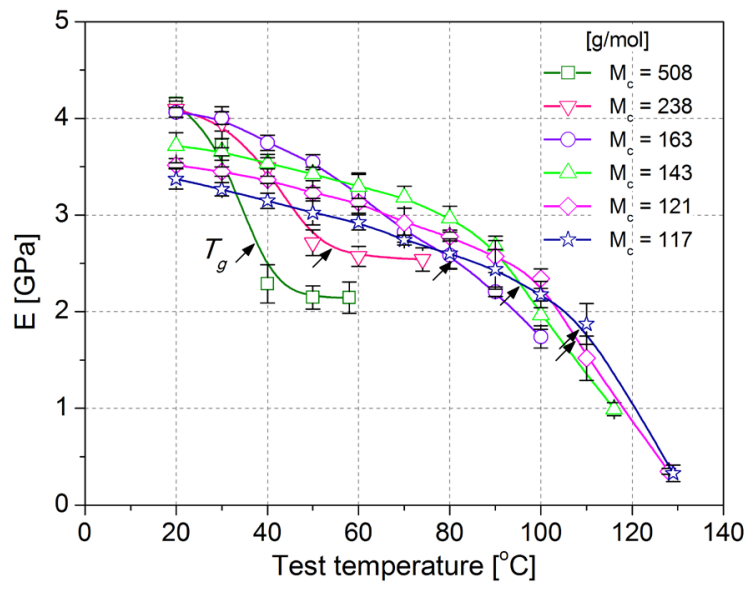

Fig. 5. Compressive Young's modulus $(E)$ versus test temperature for the EPY compound with various $M_{c}$, obtained at a standard strain rate $\left(0.208 \mathrm{~min}^{-1}\right)$

modulus of the material depends on the $M_{c}$ value and decreases distinctly with an increase of testing temperature. One should pay attention that the EPY compound with higher $M_{c}$ values, i.e. materials postcured at too low temperatures (less than $60^{\circ} \mathrm{C}$ ), have approximately the same value of $E \cong 4,1 \mathrm{GPa}$ at room temperature $\left(21^{\circ} \mathrm{C}\right)$. An expected decrease of the modulus value comes only after a distinct decrease of the $M_{c}$ value thus after raising of crosslik density. However, the material with a higher value of $M_{c}$ shows greater sensitiveness to change of testing temperature because of low cure degree. Whereas the value of the material Young modulus on the level of glass transition temperature $T_{g}$ (marked with an arrow in Fig. 5) is approximately one and a half times smaller than the $E$ value at temperature of $21^{\circ} \mathrm{C}$.

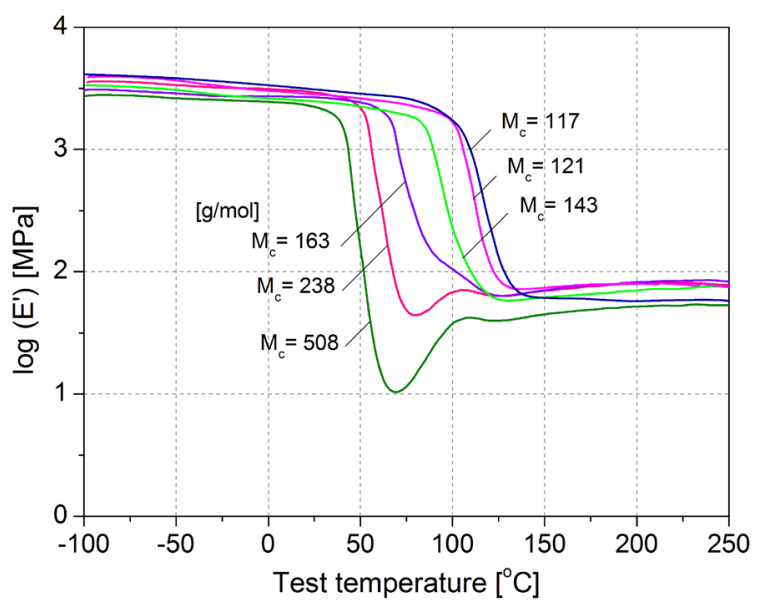

Fig. 6. Flexural storage modulus $\left(E^{\prime}\right)$ versus temperature for the EPY compound with various $M_{c}$ 
It is caused by cleavage of secondary bonds in the material during heating $[1,7]$.

Similar results for most thermosets were obtained by other authors [13, 17]. They have affirmed that the modulus does not exactly depend on the length scale parameters of the chain such as $M_{c}$ but mainly on local chain packing and stiffness of the chain [17]. It is also supported by the results from dynamic mechanical thermal analysis (DMA) for the EPY compound samples with various $M_{c}$ values which are presented in Fig. 6 showing the relationship between dynamic storage modulus $\left(E^{\prime}\right)$ and temperature (in the range from -100 to $250^{\circ} \mathrm{C}$ ).

\section{Effect of temperature on yield behaviour in compression}

The true yield stress values $\left(\sigma_{v T}\right)$ in compression of the EPY compound with various values of $M_{c}$ (from 117 to $508 \mathrm{~g} / \mathrm{mol}$ ) determined at the strain rate of $0.208 \mathrm{~min}^{-1}$ in the wide testing temperature range (from 21 to $120^{\circ} \mathrm{C}$ ) are shown in Figure 7. The relation between $\Sigma_{y T}$ and test temperature is presented in normalized co-ordinate system of $\sigma_{y T}=\mathrm{f}\left(T / T_{g}\right)$, according to adequate value of the glass transition temperature in other to show the influence of $T_{g}$ on yield behaviour of the tested material. Taking into account clearness of this figure, no insignificant standard deviations (max $3 \mathrm{MPa}$ ) for the determined values were denoted.

The $M_{c}$ value (therefore crosslink density too) is decisive as regards the value of $\sigma_{y T}$ for the material and the higher is $\sigma_{y T}$ the smaller is the $M_{c}$. Testing temperature also has a substantial effect

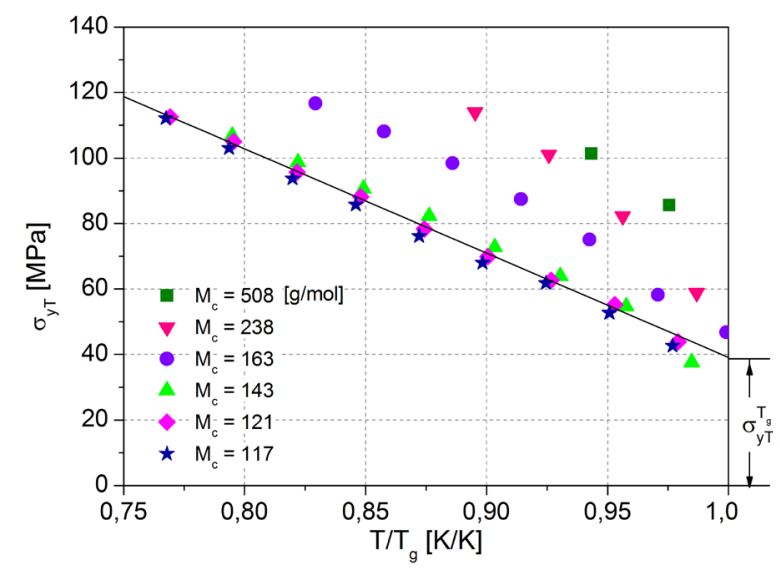

Fig. 7. Compressive true yield stress $\left(\sigma_{y T}\right)$ versus test temperature normalized by $T_{g}$ i.e. $\left(T / T_{g}\right)$ for the EPY compound with various $M_{c}$ obtained at a standard strain rate $\left(0.208 \mathrm{~min}^{-1}\right)$ on the value of $\sigma_{y T}$. This influence manifests itself in particular for unfully cured material (with a high value of $M_{c}$ ). Such material essentially changes its behaviour under load with increase in temperature that can be seen also in Figure 3a.

The yield response of a thermoset is affected by its $T_{g}$. When $T_{g}$ increases, the yield stress generally also increases for a given system (Table 1, Figs. 3 and 4). If one brings into notice the effects of temperature, the yield stress of a high $T_{g}$ network tested at a high temperature will appear to be comparable to a low $T_{g}$ network tested at a lower temperature. Thus, yield in glassy networks can be compared by shifts in test temperature and selecting $T_{g}$ as a reference temperature. However one should remember that a change in $T_{g}$ represents a difference in the actual molecular architecture of the network and a shift in temperature is only a change in the surrounding test environment. With regard to shifting with temperature, plots constructed of yield stress versus a normalized parameter of test temperature over $T_{g}\left(T / T_{g}\right)$ helps to correlate yield behavior and network stiffness of the EPY compound as shown in Figure 7.

Profile of the values of $\sigma_{v T}=\mathrm{f}\left(T / T_{g}\right)$ for every $M_{c}$ values marked in Figure 7 is linear. However for a given normalized parameter of test temperature over $T_{g}\left(T / T_{g}\right)$, an increasing the $M_{c}$ (lowering the crosslink density) raises the true yield stress value. It can be seen that in such co-ordinate system with normalized parameter (Fig. 7) the $\sigma_{v T}$ values for the EPY compound postcured at higher temperatures ranging from 80 to $120^{\circ} \mathrm{C}$ (having higher crosslink density: $0.98<\alpha<1$ [26]) overlap in a single curve corresponding to lower values of $M_{c}$ (beneath $143 \mathrm{~g} / \mathrm{mol}$ ). Good agreement of experimental results with correlation coefficient $\mathrm{R}^{2}=0.987$ was obtained here. These results show that the effect which $M_{c}$ exerts on $\sigma_{y T}$ for the investigated material manifests itself distinctly trough a change in its $T_{g}$. Similar findings were concluded in other epoxy systems by their investigators [4, $5,13,17]$. However, it can not be referred to the EPY compound with the values of $M_{c} \geq 163 \mathrm{~g} /$ mol because of too low postcuring temperature $\left(T_{c}\right.$ $\leq 60^{\circ} \mathrm{C}$ ) of the material. In this case, the obtained values of $\sigma_{y T}=\mathrm{f}\left(T / T_{g}\right)$ for the material with $M_{c}$ ranging from 163 to $508 \mathrm{~g} / \mathrm{mol}$ do not overlap in a single curve (Fig. 7). It indicates that a shift in testing temperature $T$ does not affect the yield stress in the same way as a shift in $T_{g}$. This fact means that a chemical shifting (change of $M_{c}$ ) brings an effect which is distinctly different than the changing of 
normalized parameter. Similar symptoms of thermal behaviour for epoxy systems were reported by other authors $[5,15]$.

Using the normalized parameter $\left(T / T_{g}\right)$ makes it possible to refer the yield response of an epoxy system to the intrinsic property only, namely to the $T_{g}$ that governs the yield response of this type of polymers. Thanks to that an analysis of yield behaviour of material can be facilitated. Since $T_{g}$ is affected by changes in both architecture and chemistry and these factors change the stiffness of the network, $T_{g}$ can be considered to be a physical parameter that reflects overall network stiffness. But $T_{g}$ alone is insufficient to account for differences in molecular architecture and it would be desirable to identify other else molecular parameters that govern not only architecture and chemistry but the yield behavior, too.

\section{Effect of strain rate and temperature on yield response}

Figure 8 presents the values of true yield stress in compression $\left(\sigma_{v T}\right)$ determined at different strain rates $\dot{\varepsilon}$ for the EPY compound samples with various $M_{c}$, which have been normalized by absolute temperature. As expected, the $\sigma_{v T}$ values for both cured material $\left(M_{c}=508 \mathrm{~g} / \mathrm{mol}\right)$ (Fig. 8a) and postcured one $\left(M_{c}=143 \mathrm{~g} / \mathrm{mol}\right)$ (Fig. $\left.8 \mathrm{~b}\right)$ decrease with an increase of test temperature and with a decrease in logarithm of the strain rate. A number of glassy polymers demonstrate such behaviour [6, 17] which can be described with the Eyring type flow process $[6,8,25]$. According to this theory yielding of polymer material occurs by stress-activated jumps of molecular segments, known as flow units. The application of the stress effectively lowers the activation barrier to the jumping of these molecular units causing the flow units to move in a coordinated motion which is equated with yielding.

In the Eyring theory, the shear $(\tau)$ and uniaxial $(\sigma)$ yield stress are predicted to be logarithmically related to the shear strain rate $\dot{\gamma}[6]$ :

$$
\tau=\frac{\sigma}{2}=\frac{\Delta E}{v_{f}}-\frac{k T}{v_{f}} \ln \left(\frac{\dot{\gamma}_{o}}{\dot{\gamma}}\right)
$$

where: $\Delta E$ is the activation energy, $\dot{v}_{f}$ is the activation volume (or volume of the flow unit), $k$ is the Boltzmann constant, $T$ is the absolute temperature, $\dot{\gamma}$ is the shear strain rate, and $\dot{\gamma}_{0}$ is the constant shear strain rate, which after Padmanabhan is usually taken to be about $10^{13} \mathrm{~s}^{-1}[19]$.
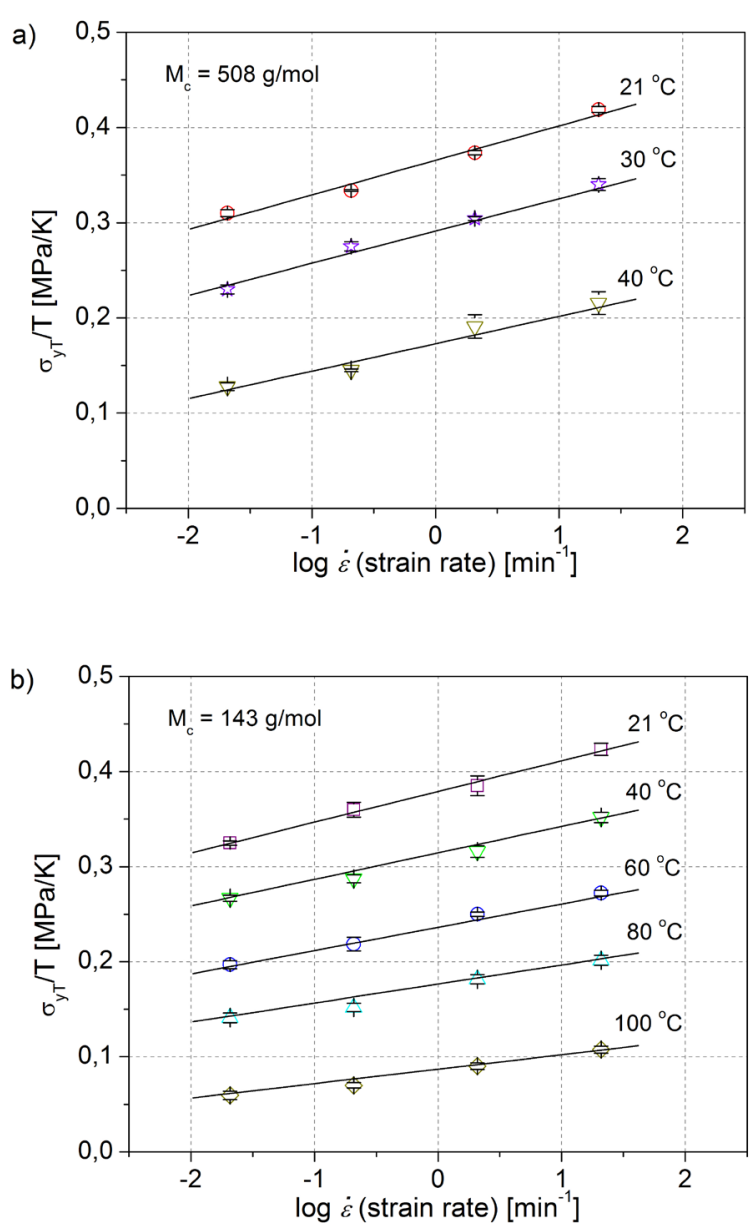

Fig. 8. Compressive true yield stress $\left(\sigma_{y T}\right)$ versus $\log$ strain rate for the EPY compound with: $M_{c}=508 \mathrm{~g} /$ $\mathrm{mol}$ (a) and $M_{c}=143 \mathrm{~g} / \mathrm{mol}$ (b), obtained at various temperatures. The solid lines concern $\sigma_{y T}$ values calculated from Eyring Eq. (4) while the symbols present the experimental results

In the presented investigations the activation energy was determined by means of software of INSTRON testing machine and the activation volume was evaluated graphically [6] as the value of tangent for inclination angle of the straight line representing $\sigma_{y T}=\log (\dot{\varepsilon})$ function.

The values of $\sigma_{y T} / T$ shown in Figure 8 were calculated by means of Eyring Eq. (4) (solid lines) and all of them demonstrate very good agreement with the experimental results (symbols) obtained for both the cured and the postcured EPY compound. It was assumed in this calculation that, the shear stress is equated to half of the compressive stress and the shear strain rate is equated to $\sqrt{2}$ times the uniaxial strain rate [6]. One can see in Figure 8 that the values of $\sigma_{y T}$ at each testing temperatures increase linearly together with logarithm of strain rate through three orders of its 
magnitude. However an inclination of the $\sigma_{y T}=\mathrm{f}$ $(\log \dot{\varepsilon})$ line decreases together with the temperature increase. It points out to desensitization of the material to changing of the strain rate. One can explain it by an increase of the activation volume (as a measure of segmental mobility) leading to a drop in the packing density and then to smaller network rigidity of the epoxy system. This sensitiveness decreases distinctly as glass transition temperature approaches when secondary crosslinks (already mentioned) undergo to disintegration.

\section{CONCLUSIONS}

Compressive and flexural tests performed on the EPY compound in different states of cure showed that the true yield stress for epoxy material does not only depend on stress value, strain rate and testing temperature but also on average molecular weight between crosslinks $\left(M_{c}\right)$. Changes in the $M_{c}$ values are reflected in diversification of network architecture of the materials because any change of $M_{c}$ is related to the change in crosslink density causing relative shift in the $T_{g}$ of the material. However, these changes do not cause a distinct drift of the glassy modulus value in the range of temperatures below $T_{g}$.

The investigations carried out with reference to the effect of network architecture on yield stress of the EPY compound showed that having affected increase in $T_{g}$ of the material, decrease of the $M_{c}$ value happens, bringing true yield stresses to be overlapped each other in the range of temperatures below $T_{g}$. It suggest that yielding in epoxy materials can be examined in categories of the Eyring's plastic flow model in which yielding is described.

The values of true yield stress in compression for the EPY compound samples with various network architecture (with different values of $M_{c}$ ) which were determined at various strain rates and normalized by absolute temperature come under decrease with a growing temperature and with a decrease of the strain rate. However, a sensitivity of the material to changes in strain rate falls down with growth of testing temperature.

Further studies are needed since network architecture affects the yielding of epoxy material not only by means of $M_{c}$ and $T_{\sigma}$ but also through other parameters, including flexibility of the chains between crosslinks.

\section{REFERENCES}

1. Ashby M.F., Jones, D.R.H.: Engineering Materials 2. An introduction to microstructures, processing and design, $3^{\text {rd }}$ Edition, Butterworth Heineman, Oxford, 2006.

2. Bandyopadhyay A., Odegard G.M.: Molecular modeling of crosslink distribution in epoxy polymers, Modelling Simul. Mater. Sci. Eng., 20, 2012, 1-22.

3. Banks L., Ellis B.: The glass transition temperatures of highly crosslinked networks: Cured epoxy resins, Polymer, 23, 1982, 1466-1472.

4. Bradley W.L., Schultz W., Corleto C., Komatsu R.: Effect of crosslink density and rubber additions on the fracture toughness of polymers, [In:] K. Riew and A. Kinloch (Eds.), Toughened Plastics I Engineering and Science, Advances in Chemistry Series, 233, American Chemical Society, Washington 1993.

5. Calzia K.J., Lesser A.J.: Correlating yield response with molecular architecture in polymer glasses, J. Mater. Sci., 42, 2007, 5229-5238.

6. Cook W.D., Mayr A.E., Edward G.H.: Yielding behaviour in model epoxy thermosets - II. Temperature dependence, Polymer, 39, 1998, 3725-3733.

7. Crawford E., Lesser A.J.: The effect of network architecture on the thermal and mechanical behavior of epoxy resins, J. Polym. Sci. B, Polym. Phys., 36, 1998, 1371-1382.

8. Eyring H.: Viscosity, plasticity, and diffusion as examples of absolute reaction rates, J. Chem. Phys., 4, 1936, 283-291.

9. Flory P.J.: Principles of polymer chemistry, Cornell Univ. Press, 1953.

10. Grudziński K., Jaroszewicz W., Ratajczak J., Urbaniak M., Grudziński P.: Mounting of machines and devices by using EPY resin compound, $\mathrm{PPH}$ ZAPOL Publisher, Szczecin 2015.

11. Haward R.N., Young R.J.: The physics of glassy polymers, $2^{\text {nd }}$ ed., Kluwer Academic Publishers, Dordrecht 1997.

12. Kaiser T.: Highly crosslinked polymers., Prog. Polym. Sci., 14, 1989, 373-450.

13. Kody R.S., Lesser A.J.: Deformation and yield of epoxy networks in constrained states of stress, J. Mater. Sci., 32, 1997, 5637-5643.

14. Kripotou S., Pissis P., Kontou E., Fainleib A.M., Grygoryeva O., Bey I.: Structure-property relationships in brittle polymer networks modified by flexible cross-links, Mater. Sci.-PL, 24, 2006, 477-492.

15. Lesser A.J., Calzia K.J.: Molecular parameters governing the yield response of epoxy-based glassy networks, J. Polym. Sci. B, Polym. Phys., 42, 2004, 2050-2056. 
16. Lesser A.J., Crawford E.: The role of network architecture on the glass transition temperature of epoxy resins, J. Appl. Polym. Sci., 66, 1997, 387-395.

17. Lesser A.J., Kody R.S.: A generalized model for the yield behavior of epoxy networks in multiaxial stress states, J. Polym. Sci. B, Polym. Phys., 35, 1997, 1611-1619.

18. Nielsen L.E.: Cross-linking. Effect on physical properties of polymers, J. Macromol. Sci. Rev. Macromol. Chem., C3, 1969, 69-103.

19. Padmanabhan K.: Time-temperature failure analysis of epoxies and unidirectional glass/epoxy composites in compression, Composites, 27A, 1996, 585-596.

20. Pearson R.A., Yee A.F.: Toughening mechanisms in elastomer-modified epoxies, J. Mater. Sci., 24, 1989, 2571-2580.

21. Rahul R., Kitey R.: Effect of cross-linking on dynamic mechanical and fracture behavior of epoxy variants, Composites Part B, 85, 2016, 336-342.

22. Sahagun C.M., Knauer K.M., S.E. Morgan: Molecular network development and evolution of nanoscale morphology in an epoxy-amine thermoset polymer, J. App. Polym. Sci., 126, 2012, 1394-1405.

23. Schroeder J.A., Madsen P.A., Foister R.T.: Structure/property relationships for a series of cross- linked aromatic/aliphatic epoxy mixtures, Polymer, 28, 1987, 929-940.

24. Sindt O., Perez J., Gerard J.F.: Molecular architecture-mechanical behaviour relationships in epoxy networks, Polymer, 37, 1996, 2989-2997.

25. Stachurski Z.H.: Deformation mechanism and yield strength in amorphous polymers, Prog. Polym. Sci., 22, 1997, 407-474.

26. Urbaniak M., Grudziński K.: Time - Temperature - Transformation (TTT) cure diagram for EPY epoxy system, Polimery, 52, 2007, 117-126.

27. Urbaniak M., Ratajczak J.: Modernization of foundations for industrial and ship's machines and devices with use of the EPY compound. Part 1. Practical applications of the EPY compound, Materials Engineering, 6, 2015, 532-536.

28. Vakil U.M., Martin G.C.: Crosslinked epoxies: Network structure characterization and physicalmechanical properties, J. Appl. Polym. Sci., 46, 1992, 2089-2099.

29. Ward I.M.: Mechanical properties of solid polymers. $2^{\text {nd }}$ ed. Wiley, 1979.

30. Yamini S., Young R.J.: The mechanical properties of epoxy resins. I. Mechanisms of plastic deformation, J. Mater. Sci., 15, 1980, 1814-1822. 